\title{
Editor's Comment
}

In this issue, you will see that we are introducing the first of a series of guest editorials. Eventually, we want two or three per issue. Topics will vary greatly, but every effort will be made to include the factual, funny, controversial, political, and so on. As a quarterly, we cannot be immediate, but we will try to stay current. We would like readers to contact us with ideas, but all editorials must be contracted with the Editor-in-Chief. Moreover, we would like spirited letters in response to the editorials and the articles and, wherever possible, these will be published.
In this issue we have a controversial editorial by Allen Roses, in whose department at Duke University the APOE story broke, regarding the utility of APOE; and an important account of Alzheimer's Disease International by its president, Nori Graham. We would like to thank them both for agreeing to make these vital contributions.

Robin Eastwood, MD Editor-in Chief St. Louis, MO, USA 